\title{
Impact of intraspecific variation on measurements of thermal tolerance in bumble bees
}

\author{
Kevin Maebe ${ }^{\mathrm{a}, *}$, Annelien De Baets ${ }^{\mathrm{a}}$, Peter Vandamme ${ }^{\mathrm{b}}$, Nicolas J. Vereecken ${ }^{\mathrm{c}}$, Denis Michez ${ }^{\mathrm{d}}$, \\ Guy Smagghe ${ }^{\text {a }}$ \\ ${ }^{a}$ Laboratory of Agrozoology, Department Plants and Crops, Faculty of Bioscience Engineering, Ghent University, Coupure Links 653, 9000, Ghent, Belgium \\ ${ }^{\mathrm{b}}$ Laboratory of Microbiology, Department of Biochemistry and Microbiology, Faculty of Sciences, Ghent University, K. L. Ledeganckstraat 35, 9000, Ghent, Belgium \\ ${ }^{c}$ Agroecology Lab, Université libre de Bruxelles (ULB), Boulevard du Triomphe CP 264/02, 1050, Brussels, Belgium \\ d Laboratory of Zoology, Research Institute for Biosciences, University of Mons, Place du parc 20, 7000, Mons, Belgium
}

\section{A R T I C L E I N F O}

\section{Keywords:}

Critical thermal limits

Thermal tolerance

Bombus terrestris

Subspecies

Castes

Body size

\begin{abstract}
A B S T R A C T
Climate change is an important driver of bee decline despite the fact that many species might respond to climate change differently. One method to predict how a species will respond to climate change is to identify its thermal tolerance limits. However, differences in thermal tolerance might also occur among distant populations of the same species based on their local environment or even among castes of social insects. Here, we investigated intraspecific differences in thermal tolerance among subspecies of the large earth bumble bee, Bombus terrestris (Apidae). We determined the critical thermal minima and maxima $\left(\mathrm{CT}_{\min }\right.$ and $\mathrm{CT}_{\max }$, respectively) of workers and queens from three lab-reared B. terrestris subspecies (B. t. terrestris, B. t. audax, and B. t. canariensis) which originated from different thermal environments. Our results showed that caste has an influence on critical thermal minima, with queens being most cold-tolerant, but the values of critical thermal maxima were not correlated to caste or size. The thermal tolerance of workers did not differ among the subspecies. Although heat tolerance was similar in queens, $B$. $t$. canariensis queens (originating from the warmest environments) were the least cold tolerant. Overall, we showed that $B$. terrestris may be generally robust against climate warming, but that particular subspecies and/or populations may be more vulnerable to extreme temperature variability. Future research should focus on responses of $B$. terrestris populations to short, extreme thermal events.
\end{abstract}

\section{Introduction}

Bumble bees are important pollinators of many wild flowers and crops (Velthuis and Doorn, 2006; Goulson, 2010). Although playing an essential part in many ecosystems, their survival is under threat by multiple threats, including agricultural intensification, urbanization, pesticide usage, spread of pathogens, and climate change (e.g. Potts et al., 2010; Vanbergen et al., 2013; Cameron and Sadd, 2020). Climate change is thought to be one of the major drivers of the ongoing bee decline at least for some groups like bumble bees (e.g. Bartomeus et al., 2011; Rasmont et al., 2015), with global warming causing spatial shifts and phenology mismatches (Kerr et al., 2015; Pyke et al., 2016; Gerard et al., 2020), particularly when in association with land use changes (Marshall et al., 2018). Furthermore, climate change can also affect local and regional persistence of populations and species through the impact of extreme weather events (both hot and cold) on the colony performance and survival (Owen et al., 2013; Rasmont et al., 2015; Martinet et al., 2015).

The capacity of bumble bees to overcome unfavorable thermal conditions depends largely on their thermal tolerance (Oyen et al., 2016; Oyen and Dillon, 2018), as well as on behavior and microhabitat selection (Abram et al., 2017). Thermal tolerance can be assessed by the minimum and maximum critical temperature $\left(\mathrm{CT}_{\min }\right.$ and $\left.\mathrm{CT}_{\max }\right)$, which is essentially the coldest and hottest temperature at which a species can maintain muscle control (Oyen et al., 2016; Robertson et al., 2017; Oyen and Dillon, 2018). Reaching a better understanding of critical thermal limits through adequate experiments can help to determine a species physiological vulnerability to climate change which in turn may help to predict how species respond to changes in temperature (Deutsch et al., 2008; Kellerman et al., 2012; Hamblin et al., 2017; Burdine and McCluney, 2019). Interspecific variation has been already described in previous studies. In Hamblin et al. (2017), the authors showed high

\footnotetext{
* Corresponding author.

E-mail address: kevin.maebe@ugent.be (K. Maebe).
} 
interspecific variability of $\mathrm{CT}_{\max }$ among 15 bee species, with lowest $\mathrm{CT}_{\text {max }}$-values in solitary bee and bumble bee species. By measuring hyperthermic resistance in males of 10 bumble bee species, Zambra et al. (2020) found a species-specific thermal sensitivity in bumble bees, with widespread species, such as $B$. terrestris and $B$. lucorum, being least sensitive, while declining species, such as $B$. jonellus and $B$. magnus, being most vulnerable to the induced thermal stress. Furthermore, Oyen et al. (2016) showed that bumble bee species inhabiting higher altitude have a larger thermal tolerance breadth (where TTB $=\mathrm{CT}_{\max }-\mathrm{CT}_{\min }$ ) than species from the valley, in correlation with the climatic amplitude of their habitat. The latter can be explained by two general patterns in thermal tolerance: Janzen's rule (Janzen, 1967), or the climate variability hypothesis, in which species thermal tolerance breath will increase with latitude due to greater climate variability, and Brett's rule (Brett, 1956) which states that more geographic variation occurs in lower than in upper thermal limits (Bishop et al., 2017; Sunday et al., 2019). Expanding insect populations will experience colder climatic conditions when moving to higher latitudes, which in turn will trigger stronger selection pressures on cold hardiness than on heat tolerance (Sunday et al., 2011, 2014; Lancaster 2016).

Selection or phenotypic plasticity on various traits are proposed to explain interspecific and intraspecific variation of thermal tolerance, including to the recent global climate changes (Angilletta, 2009; Brans et al., 2017; Diamond et al., 2017; Martin et al., 2019). One trait that might be related to thermal tolerance is body size. The ratio between body surface and volume has indeed some impact on heat loss, smaller individuals being less prone to or efficient at heat retention, and as a result they are less likely to forage at low temperatures. In social insects, like bumble bees, it is generally assumed that larger workers and queens can forage at low temperatures, and that they are more susceptible to overheating (Heinrich, 1993; Goulson, 2010). However, Oyen et al. (2016) found an opposite trend, namely that smaller sized workers of B. bifarius living at higher altitudes (and thus colder climatic conditions) were able to tolerate colder air temperatures.

Bumble bee queens might also show different thermal tolerances than workers, not because they are much larger, but as they are the only bumble bee caste which is able to survive the unseasonable thermal conditions during winter (Alford, 1975; Goulson, 2010). Queens go in hibernation in which they need to carefully regulate their metabolism, activity level, and energy reserves (Heinrich, 1979; Goulson, 2010). By lowering the metabolic rate, hibernating queens are able to perform basic cellular maintenance (Hahn \& Denlinger, 2007, 2011), but at the same time they save their energy reserves for later (Denlinger, 2002). Bumble bee queens might thus have specific adaptations which enable them to tolerate much colder thermal conditions than workers.

In this study, we focus on Bombus terrestris, one of the most abundant bumble bee species in Europe, ranging from the Mediterranean to South Scandinavia, excluding arctic, alpine, and desert regions (Rasmont et al., 2008; Lecocq et al., 2016). Nine subspecies are known within this range, each occupying environments with different climatic conditions (Rasmont et al., 2008). Each of these subspecies can be expected to have evolved intraspecific adaptations to cope with the different temperatures they endure. We therefore investigated variation in the critical thermal limits (TTB) of both workers and queens of three recently domesticated subspecies of B. terrestris (B. t. terrestris, B. t. audax and B.t. canariensis). These subspecies originate from environments with different thermal conditions, with B. t. terrestris living in most parts of continental Europe north of the 45th parallel, while B. t. canariensis, and B. t. audax can be solely found in the Canary and British Islands, respectively (Rasmont et al., 2008; Lecocq et al., 2016). We measured the $\mathrm{CT}_{\min }$ and $\mathrm{CT}_{\max }$ of both workers and queens (see also Oyen and Dillon, 2018), and examined whether body size and mass could influence thermal limits. Based on literature, we can theoretically expect a significant level of interspecific responses to climate change in bumble bees, along with a potential variation in intraspecific thermal tolerance. And this particularly in species whose distribution range includes a large gradient of climatic conditions with different subspecies associated to habitats with contrasting environmental conditions, and between castes which are exposed to different temporal, thermal conditions. So, we hypothesize to see intraspecific differences in both cold and heat tolerances in bumble bees, with (i) B. t c canariensis originating from the hottest and most stable environment showing the highest heat tolerance and smallest TTB, following the climate variability hypothesis, and (ii) a difference in cold tolerance among caste per subspecies, with queens being more cold tolerant than workers. Furthermore, this approach will provide insight about whether intraspecific variation in thermal tolerance should be accounted for when predicting how bumble bee species will react to and cope with ongoing and future climatic change.

\section{Material and methods}

\subsection{Selection of subspecies and specimen}

All three selected subspecies (B. t. terrestris, B. t. audax and B. t. canariensis) are commercially bred for multiple generations under standardized thermal conditions, the breeding of $B$. t. terrestris being the oldest and dated back from the 1980's (Velthuis and van Doorn, 2006), while breeding of $B$. $t$. audax for the British market is a more recent practice. However, we made the assumption that the relatively short time of domestication process did not alter potential climatic adaption to their native region. Moreover, we characterized climatic conditions of the native area of each three selected subspecies, based on the extracted climate data from Copernicus Climate Change Service C3S (2020) (monthly average temperature of: daily average, daily maximum, and daily minimum) for the period 1981-2010. We consider several locations within the full geographic range of each subspecies (see Supplementary Tables 1-3; Copernicus Climate Change Service C3S, 2020), and two distinctly different thermal environments were present (Fig. 1). The Canary Islands yearly minimum, average, and maximum of monthly average temperature $\left(17.8{ }^{\circ} \mathrm{C}, 20.4{ }^{\circ} \mathrm{C}\right.$ and $23.4{ }^{\circ} \mathrm{C}$, respectively) were clearly hotter than those found within the natural distribution of the other subspecies (for B. t. audax in the UK: $-1.0^{\circ} \mathrm{C}, 9.0^{\circ} \mathrm{C}$ and $20.5^{\circ} \mathrm{C}$; and for B. t. terrestris in mainland Europe: $-10.9^{\circ} \mathrm{C}, 8.2^{\circ} \mathrm{C}$ and $24.4^{\circ} \mathrm{C}$, respectively). Although in general the thermal conditions for $B$. $t$. terrestris and B. t. audax seem very similar, B. t. terrestris encounters annually more extreme cold and warm temperatures (Fig. 1).

A total of 153 bumble bees: 27, 29 and 27 workers and 21, 24 and 25 queens from subspecies B. t. audax, B. t. canariensis and B. t. terrestris, respectively, were obtained from a mass-rearing facility for biological pollination (Biobest, Westerlo, Belgium). The rearing conditions for colonies of all three subspecies were similar: $25-30{ }^{\circ} \mathrm{C}, 40-60 \%$ air humidity, and permanent darkness (Pers. Comm., Lieve Vandendriessche, Biobest). Maximum one worker and queen were randomly selected from the same colony. Individual bees were placed in single housing cages, fed ad libitum with 50\% sugar water (BioGluc, Biobest) and kept under standardized conditions of $25{ }^{\circ} \mathrm{C}, 60-65 \%$ air humidity and permanent darkness.

\subsection{Experimental setup}

Workers or queens (a maximum of 12 at a time, four of each subspecies) were placed individually within queen bee marking cages and stored in a MIR-254-PE (PHCbi, Japan) cooled incubator without food and in continuous darkness at $10{ }^{\circ} \mathrm{C}$ for $30 \mathrm{~min}$. A queen bee marking cage consists of a plastic cylinder $(3.1 \mathrm{~cm}$ in diameter and $8.3 \mathrm{~cm}$ of length), a plastic cover with rectangular meshes $(0.5 \times 0.6 \mathrm{~cm})$ for ventilation, and a wooden plunger to trap a bee queen (but can also be used to trap bumble bee workers). Incubator temperature was ramped to $-10^{\circ} \mathrm{C}$ at a rate of $\sim 0.5^{\circ} \mathrm{C} / \mathrm{min}$ into determine $\mathrm{CT}_{\min }$. Afterwards, bees were reheated (at a rate of $\sim 0.35^{\circ} \mathrm{C} / \mathrm{min}$ ) and kept at $20^{\circ} \mathrm{C}$ for $30 \mathrm{~min}$. To obtain $\mathrm{CT}_{\max }$, of the same specimens after measurement of $\mathrm{CT}_{\min }$, the incubator was then heated to $60{ }^{\circ} \mathrm{C}$ at a rate of $\sim 0.35{ }^{\circ} \mathrm{C} / \mathrm{min}$. The 

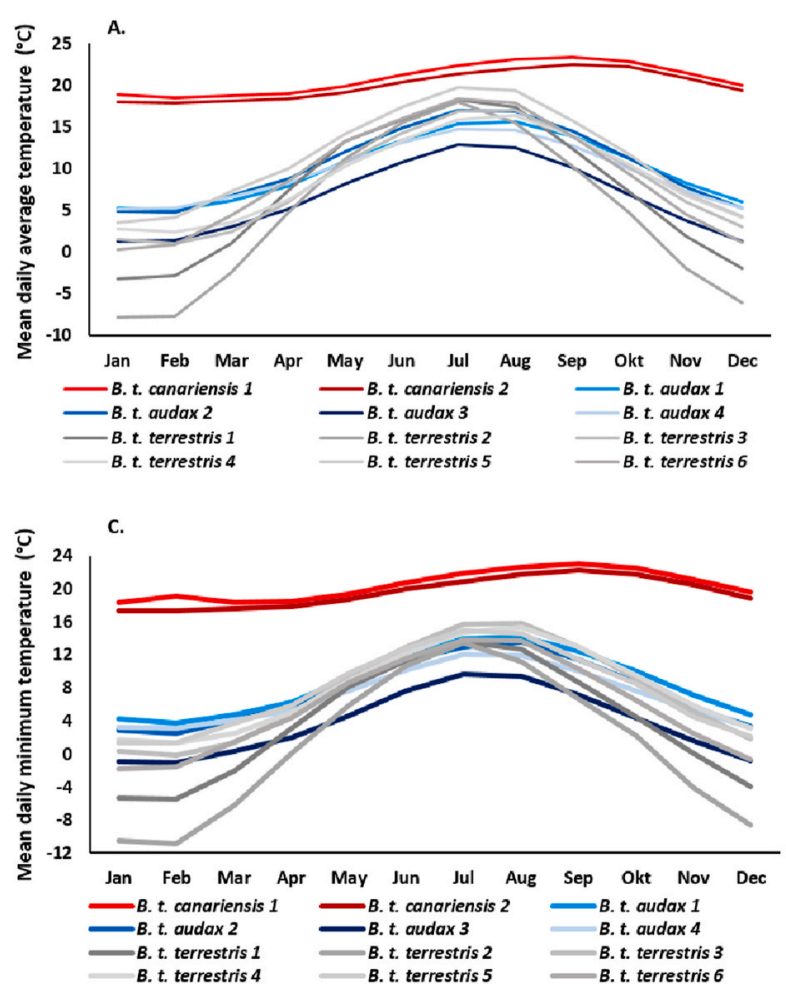

B.

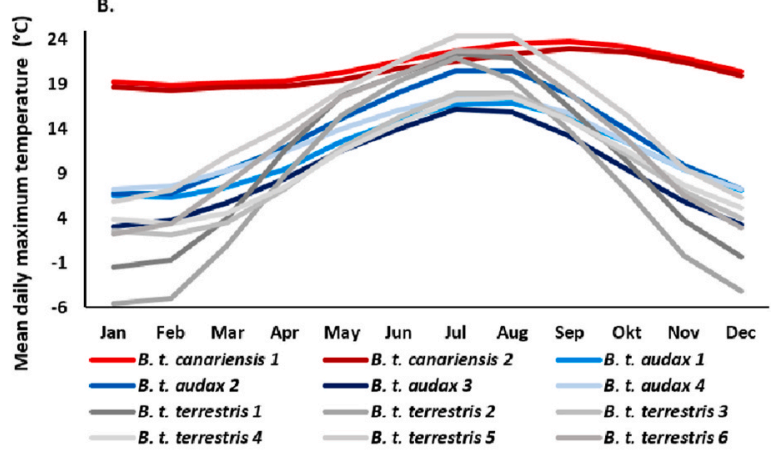

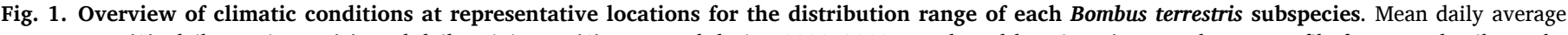

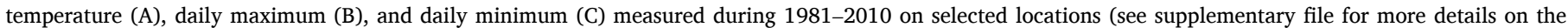
locations). Data obtained from Copernicus Climate Change Service C3S (2020).

measurement of $\mathrm{CT}_{\max }$ immediately after that of $\mathrm{CT}_{\min }$ was based on a similar approach as described in Oyen and Dillon (2018) (and see also additional refs herein); where was shown that this did not affect the accuracy of the $\mathrm{CT}_{\max }$ measurement. The entire experiment lasted approximately $5 \mathrm{~h}$. Worker and queen body temperatures (=thorax surface temperatures; $\mathrm{CT}_{\min }$ (thorax) and $\mathrm{CT}_{\max }$ (thorax)), together with ambient (cage) temperatures $\left(\mathrm{CT}_{\min }\right.$ and $\left.\mathrm{CT}_{\max }\right)$ were continuously monitored during the full length of the experiment using an Optris PI 160 IR camera (Optris, Berlin, Germany) placed on a retort stand, $35 \mathrm{~cm}$ above the queen bee marking cages. Thermal data were obtained from each specimen using the supplied software Optris PIX Connect, at $1 \mathrm{~s}$ intervals. To determine the specific point of $\mathrm{CT}_{\min }$ and $\mathrm{CT}_{\max }$, each specimen was also continuously monitored using a c920 HD Pro webcam (Logitech, Lausanne, Switzerland) which was placed on the retort stand within the incubator. After the experiment ended, each movie was carefully watched to find the time point at which each bee performed the stereotypical curling and spasming behavior when reaching $\mathrm{CT}_{\min }$ and $\mathrm{CT}_{\text {max }}$, respectively (see Oyen and Dillon, 2018). These time points were then used to determine the corresponding temperatures (both $\mathrm{CT}_{\min }$ and $\mathrm{CT}_{\max }^{;}$and $\mathrm{CT}_{\min }$ (thorax) and $\mathrm{CT}_{\max }$ (thorax)) measured with the IR camera. Bee body mass was measured as the average dry weight from three repeated measurements, and body size was determined by measuring the inter-tegular span (ITS) from video snapshots using Image J (Abramoff et al., 2004).

\subsection{Analyses}

Statistics and data processing were performed using SPSS version 25 (IBM, 2017). To assess differences in thermal limits between subspecies, we performed one-way ANOVAs for workers and queens separately, followed by Tukey HSD post-hoc comparisons including a Bonferroni correction for multiple comparisons. Furthermore, one-way ANOVAs were also done to investigate differences between castes overall subspecies and within each subspecies. Finally, to investigate whether body size and mass have any effect on bees' thermal tolerance, we normalized bees' thermal limits by dividing it by their body size, or their body mass. Afterwards, one-way ANOVAs were performed to search for significant differences.

\section{Results}

\subsection{Variation of cage and thorax surface $C T_{\min }$ and $C T_{\max }$ among subspecies}

Mean $\mathrm{CT}_{\min }( \pm \mathrm{SD})$ of workers was similar in B. t. audax, B. t. canariensis and $B$. t. terrestris $\left(-3.9^{\circ} \mathrm{C} \pm 0.5,-3.8^{\circ} \mathrm{C} \pm 0.5\right.$ and $-5.1{ }^{\circ} \mathrm{C} \pm$ 0.6; respectively; Supplementary Table 4$)\left(\mathrm{CT}_{\min }\right.$, one-way ANOVA, $F=$ 1.804, $P=0.171$, Fig. $2 \mathrm{~A}$ ). The $\mathrm{CT}_{\min }$ (thorax) was $\pm 6^{\circ} \mathrm{C}$ higher, with a mean $\mathrm{CT}_{\min }$ (thorax) of $2.2{ }^{\circ} \mathrm{C} \pm 0.2,1.9^{\circ} \mathrm{C} \pm 0.2$, and $1.6{ }^{\circ} \mathrm{C} \pm 0.2$, respectively; Supplementary Table 4). We found no significant differences in $\mathrm{CT}_{\max }$ between workers of the three subspecies $\left(50.0^{\circ} \mathrm{C} \pm 0.5\right.$, $50.2{ }^{\circ} \mathrm{C} \pm 0.3$ and $49.6{ }^{\circ} \mathrm{C} \pm 0.5$; respectively) (one-way ANOVA, $F=$ $0.558, P=0.576$; respectively; Fig. $2 \mathrm{~A}$ ). The worker thorax surface temperatures were $\pm 2{ }^{\circ} \mathrm{C}$ lower, being $48.3^{\circ} \mathrm{C} \pm 0.4,48.4^{\circ} \mathrm{C} \pm 0.2$, and $47.3^{\circ} \mathrm{C} \pm 0.4$ for the three respective subspecies.

The $\mathrm{CT}_{\min }$ differed significantly among queens (one-way ANOVA, $F$ $=4.560, P=0.014)$. Bombus $t$. Canariensis queens had significantly higher mean $\mathrm{CT}_{\min }$ values $\left(-6.4^{\circ} \mathrm{C} \pm 0.3\right)$ than observed for $B$. t. audax $\left(-7.8^{\circ} \mathrm{C} \pm 0.4\right.$; Tukey HSD, $\left.P=0.028\right)$ and for B. t. terrestris $\left(-7.5^{\circ} \mathrm{C} \pm\right.$ 0.4; Tukey HSD, $P=0.032$; Supplementary Table 4 and Fig. 2B). The mean $\mathrm{CT}_{\min }$ (thorax) was $0.8^{\circ} \mathrm{C} \pm 0.4$ in B. t. audax, $1.2^{\circ} \mathrm{C} \pm 0.3$ in B. $t$. canariensis, and $-1.4{ }^{\circ} \mathrm{C} \pm 0.3$ in B. t. terrestris (Supplementary Table 4). Mean $\mathrm{CT}_{\max }$ was $49.8{ }^{\circ} \mathrm{C} \pm 0.5,49.9{ }^{\circ} \mathrm{C} \pm 0.5$ and $50.1{ }^{\circ} \mathrm{C} \pm 0.4$ for queens of B. t. audax, B. t. canariensis and B. t. terrestris, respectively (Supplementary Table 4). Like in workers, no significant differences for $\mathrm{CT}_{\max }$ were found among queens of the different subspecies (one-way ANOVA, $F=0.161, P=0.852$ ). Finally, the mean $\mathrm{CT}_{\max }$ (thorax) was $48.0^{\circ} \mathrm{C} \pm 0.5,48.3^{\circ} \mathrm{C} \pm 0.4$ and $48.4{ }^{\circ} \mathrm{C} \pm 0.5$ for queens of $B$. t. audax, 


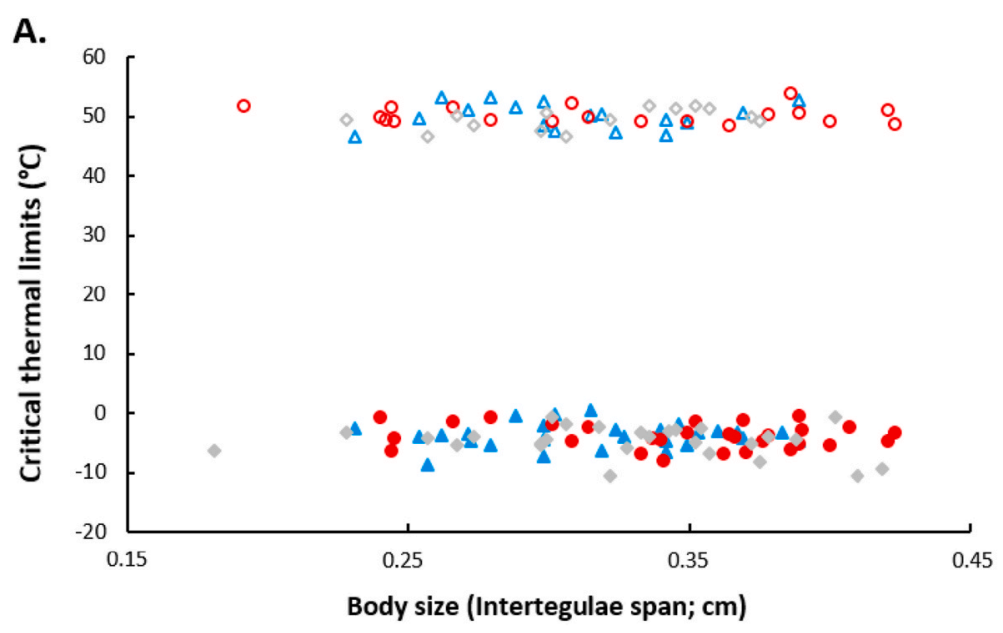

B.

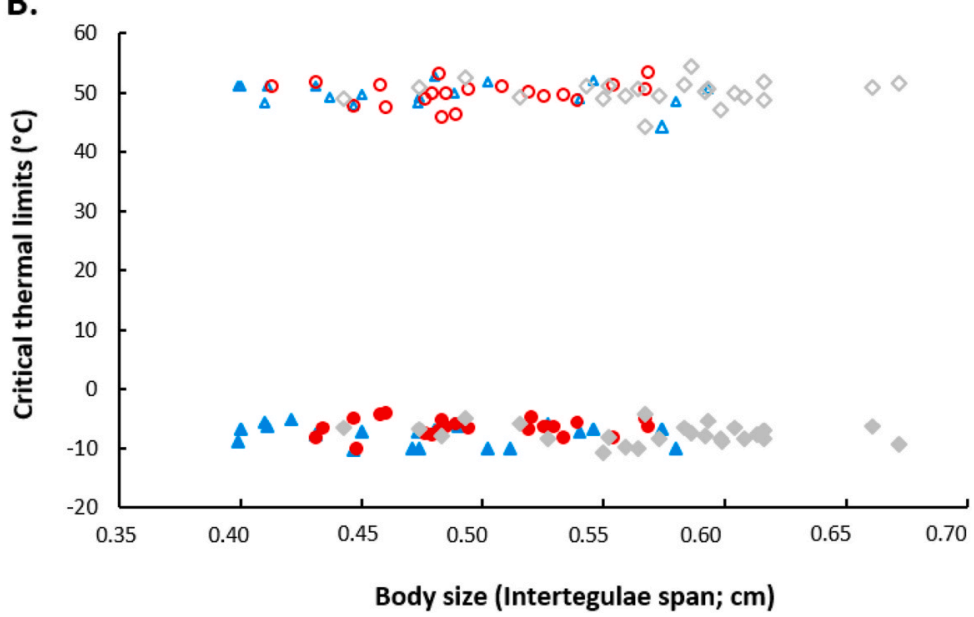

$\triangle$ CTmin_B.t. audax

- CTmin_B.t. canariensis

CTmin_B.t. terrestris

$\triangle$ CTmax_B.t. audax

o CTmax_B. t. canariensis

CTmax_B. t. terrestris

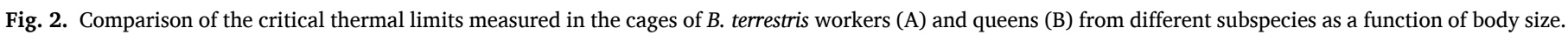

B. t. canariensis and B. t. terrestris, respectively (Supplementary Table 4).

\subsection{Variation of $C T_{\min }$ and $C T_{\max }$ between castes}

The $\mathrm{CT}_{\min }$ differed significantly between castes when grouping all workers and queens, with queens being more cold tolerant $\left(-4.1^{\circ} \mathrm{C} \pm\right.$ 2.2 vs $-7.2{ }^{\circ} \mathrm{C} \pm 1.7$, respectively; one-way ANOVA, $F=87.329, P<$ 0.001). The same difference occurred also within each subspecies (B. $t$. audax, workers $=-3.9^{\circ} \mathrm{C} \pm 0.5$, queens $=-7.8^{\circ} \mathrm{C} \pm 0.4$; one-way ANOVA, $F=45.103, P<0.001 ; B$. $t$. canariensis, workers $=-3.8{ }^{\circ} \mathrm{C}$ \pm 0.5 , queens $=-6.4{ }^{\circ} \mathrm{C} \pm 0.3$; one-way ANOVA, $F=26.694, P<0.001$; B. $t$. terrestris, workers $=-5.1^{\circ} \mathrm{C} \pm 0.6$, queens $=-7.5{ }^{\circ} \mathrm{C} \pm 0.4$; oneway ANOVA, $F=20.495, P<0.001$; Supplementary Table 4 and Fig. 3A).

In contrast, no significant differences between castes were found for $\mathrm{CT}_{\text {max }}$. Indeed, $\mathrm{CT}_{\max }$ was similar between castes when grouping all workers $\left(50.0{ }^{\circ} \mathrm{C} \pm 0.3\right)$ and queens $\left(50.1{ }^{\circ} \mathrm{C} \pm 0.2\right)$ of the three subspecies together (one-way ANOVA, $F=0.009, P=0.923$ ), and also within each subspecies (B. $t$. audax, workers $=50.0^{\circ} \mathrm{C} \pm 0.5$, queens $=$ $49.8^{\circ} \mathrm{C} \pm 0.5$, one-way ANOVA, $F=0.084, P=0.773 ; B$. t. canariensis, workers $=50.2{ }^{\circ} \mathrm{C} \pm 0.3$, queens $=-49.9{ }^{\circ} \mathrm{C} \pm 0.5$, one-way ANOVA, $F$ $=0.132, P=0.718 ; B$. $t$. terrestris, workers $=49.6{ }^{\circ} \mathrm{C} \pm 0.5$, queens $=$ $-50.1^{\circ} \mathrm{C} \pm 0.4$, one-way ANOVA, $F=0.765, P=0.388$; Supplementary Table 4 and Fig. 3B).

\subsection{Effect of body size and mass on critical thermal limits}

In workers, body size did not differ among subspecies, with ITS being
$0.316 \mathrm{~cm} \pm 0.008,0.346 \mathrm{~cm} \pm 0.010$, and $0.327 \mathrm{~cm} \pm 0.011$ for $B . t$. audax, B. t. canariensis, and B. t. terrestris, respectively (one-way ANOVA, $F=2.529, P=0.086$; Fig. 2A). Furthermore, worker body size did not correlate with $\mathrm{CT}_{\min }$ or $\mathrm{CT}_{\max }$ when pooled over all subspecies $(\mathrm{r}=$ $-0.111, P=0.319$ and $\mathrm{r}=0.079, P=0.585$, respectively) nor within each of the three subspecies separately $(P>0.05$; Supplementary Fig. 1$)$. Bombus $t$. Terrestris queens were significantly larger (ITS: $0.560 \mathrm{~cm} \pm$ 0.011 ; one-way ANOVA, $F=19.925, P<0.001$ ) than those of $B$. t. audax (ITS: $0.477 \mathrm{~cm} \pm 0.012$; Tukey HSD, $P<0.001)$ or $B$. t. canariensis (ITS: $0.491 \mathrm{~cm} \pm 0.011$; Tukey HSD, $P<0.001$ ) (Fig. 2B). Although B. $t$. terrestris queens were larger bees, overall subspecies size was not correlated with $\mathrm{CT}_{\min }$ or $\mathrm{CT}_{\max }(\mathrm{r}=-0.148, P=0.220$ and $\mathrm{r}=0.010, P$ $=0.937$, respectively). Even within the three subspecies size showed no significant correlation with $\mathrm{CT}_{\min }$ or $\mathrm{CT}_{\max }(P>0.05$; Supplementary Fig. 2).

As expected, the analysis of body mass showed similar results as for worker body size, with no difference between subspecies (B. t. audax, $0.229 \mathrm{~g} \pm 0.009 ; B$. t. canariensis, $0.262 \mathrm{~g} \pm 0.013$; and $B$. t. terrestris, $0.327 \mathrm{~g} \pm 0.011$; one-way ANOVA, $F=1.698, P=0.189$ ), and no correlation with $\mathrm{CT}_{\min }$ or $\mathrm{CT}_{\max }$ over all subspecies $(\mathrm{r}=-0.110, P=0.315$ and $\mathrm{r}=0.044, P=0.762$, respectively) nor within each subspecies $(P>$ 0.05; Supplementary Fig. 3). While B. t. terrestris queens were significantly heavier (0.989 $\mathrm{g} \pm 0.023$; one-way ANOVA, $F=29.307, P<$ $0.001)$ than B.t. audax (0.806 \pm 0.021 ; Tukey HSD, $P<0.001)$ and B. $t$ canariensis queens $(0.831 \mathrm{~g} \pm 0.028$; Tukey HSD, $P<0.001)$, also no significant correlation of body size with $\mathrm{CT}_{\min }$ or $\mathrm{CT}_{\max }$ was present in queens over all subspecies $(\mathrm{r}=-0.112, P=0.352$ and $\mathrm{r}=0.086, P=$ 0.506 , respectively), and within subspecies $(P>0.05$; Supplementary 


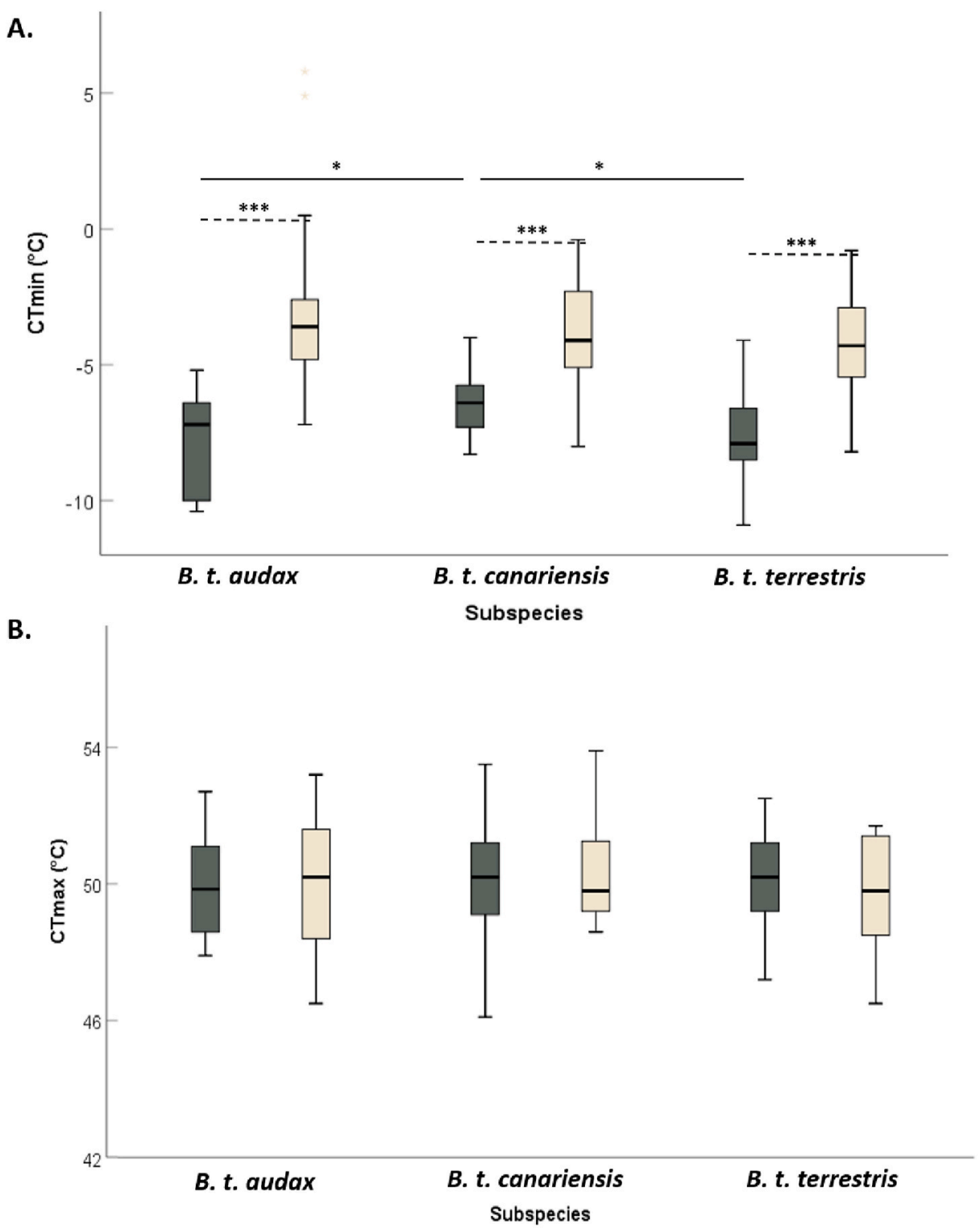

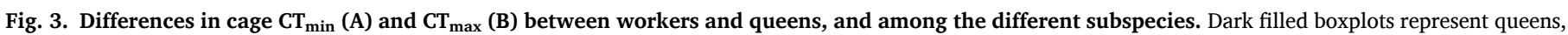
while light boxplots symbolize workers. With $*=P<0.05$ and $* * *=P<0.001$, see manuscript for the statistical analysis.

Fig. 4).

$\mathrm{CT}_{\min }$-values were significantly different between castes. However, as workers and queens differed also significantly in body size and mass, normalization of $\mathrm{CT}_{\min }$ by body size and mass was performed to unravel whether the observed difference between castes was caused by biophysical or physiological differences. After normalization by the bee's body mass, $\mathrm{CT}_{\min }$ still differed significantly between castes, and this overall specimens (workers $=-16.3 \pm 1.2$, queens $=-8.3 \pm 0.3$, oneway ANOVA, $F=37.36, P<0.001$ ) and within each subspecies (B. $t$. audax, workers $=-16.1 \pm 1.9$, queens $=-9.6 \pm 0.5$, one-way ANOVA, $F=8.765, P=0.005 ;$ B. $t$. canariensis, workers $=-13.4 \pm 1.4$, queens $=$ $-7.9 \pm 0.4$, one-way ANOVA, $F=11.983, P<0.001 ; B$. $t$. terrestris, workers $=-19.6 \pm 2.6$, queens $=-7.7 \pm 0.4$, one-way ANOVA, $F=$ $18.893, P<0.001)$. However, normalization by body size, resulted in no significant difference of $\mathrm{CT}_{\min }$ between castes overall specimens (workers $=-12.8 \pm 0.8$, queens $=-14.3 \pm 0.4$, one-way ANOVA, $F=$ $2.150, P=0.145)$ nor within the subspecies (B. $t$. canariensis, one-way ANOVA, $F=2.115, P=0.152$; and $B$. $t$. terrestris, one-way ANOVA, $F$ $=0.913, P=0.344$ ), except in $B . t$. audax (workers, $-12.3 \pm 1.4,-16.3$

\pm 0.8 queens, one-way ANOVA, $F=4.9033, P=0.032$ ).

\section{Discussion}

\subsection{Thermal tolerance in B. terrestris workers}

No intraspecific variation in thermal tolerance was found between workers of three $B$. terrestris subspecies. Workers of the three $B$. terrestris subspecies had similar $\mathrm{CT}_{\min }$ and $\mathrm{CT}_{\max }\left(\sim-4.5{ }^{\circ} \mathrm{C}\right.$ and $\sim 50{ }^{\circ} \mathrm{C}$, respectively). $\mathrm{CT}_{\max }$ of $B$. terrestris workers was similar to those obtained in lab-reared and wild $B$. impatiens workers $\left(\sim 53^{\circ} \mathrm{C}\right.$; Oyen and Dillon, 2018; Burdine and McCluney, 2019); to workers of other social insects such as honey bees (Apis mellifera) $\left(\sim 50{ }^{\circ} \mathrm{C}\right.$; Kovac et al., 2014; Sánchez-Echeverría et al., 2019) and of 26 ant species (mean $\mathrm{CT}_{\max }$ of $48-50{ }^{\circ} \mathrm{C}$; ranging from $42.0^{\circ} \mathrm{C}$ to $58.6{ }^{\circ} \mathrm{C}$; Bujan et al., 2020); and even to several solitary bee species (ranging from $44.6^{\circ} \mathrm{C}$ to $51.1^{\circ} \mathrm{C}$; Hamblin et al., 2017). $\mathrm{CT}_{\min }$ for $B$. terrestris workers was much lower compared to bumble bee workers of $B$. impatiens $\left(\sim 4{ }^{\circ} \mathrm{C}\right.$; Oyen and Dillon, 2018), wild-caught bumble bee workers of $B$. huntii, B. sylvicola and B. bifarius (7-10 ${ }^{\circ} \mathrm{C}$; Oyen et al., 2016), honey bees workers $\left(\sim 9{ }^{\circ} \mathrm{C}\right.$; Sánchez-Echeverría et al., 2019), and the workers of 28 mountain ant species $\left(\mathrm{CT}_{\min }\right.$ between $0.3^{\circ} \mathrm{C}$ and $6.3^{\circ} \mathrm{C}$; Bishop et al., 2017). However, 
the $\mathrm{CT}_{\min }$ values we measured were similar to mean $\mathrm{CT}_{\min }$ values of B. bifarius, B. flavifrons and B. mixtus workers $\left(-2.7{ }^{\circ} \mathrm{C},-2.6{ }^{\circ} \mathrm{C}\right.$ and $-3.3^{\circ} \mathrm{C}$, respectively; Dotson, 2017), to recent reported $\mathrm{CT}_{\min }$-values of workers from B. vosnesenskii colonies (up to $-7^{\circ} \mathrm{C}$, Pimsler et al., 2020), and to the lethal limits of B. t. audax obtained by Owen et al. (2013), ranging from $-5{ }^{\circ} \mathrm{C}$ to $-9{ }^{\circ} \mathrm{C}$. Some discrepancies among $\mathrm{CT}_{\min }$ estimates may be due to differences in the method used. For instance, Oyen et al. (2016) used a righting response assay (with $\mathrm{CT}_{\min }=$ highest chamber air temperature at which a bee was unable to right itself within 30s after being flipped), while Dotson (2017), Oyen and Dillion (2018), and Pimsler et al. (2020) all used another method to measure $\mathrm{CT}_{\min }$. In their method, individual workers were placed in vials, which in turn were placed in specially designed wells in a solid aluminum block attached to an insulated thermoelectric plate. While cooling the bees at $0.25{ }^{\circ} \mathrm{C} / \mathrm{min}, \mathrm{CT}_{\min }$ was measured as the vial temperature at which workers went in chill coma (Dotson, 2017; Oyen and Dillion, 2018; Pimsler et al., 2020). Although the same method to measure $\mathrm{CT}_{\min }$ was used, it resulted in large differences in $\mathrm{CT}_{\mathrm{min}}$-values for workers of B. impatiens ( $\sim 4^{\circ} \mathrm{C}$; Oyen and Dillon, 2018), B. bifarius, B. flavifrons and B. mixtus workers $\left(-2.7^{\circ} \mathrm{C},-2.6^{\circ} \mathrm{C}\right.$ and $-3.3^{\circ} \mathrm{C}$, respectively; Dotson, 2017), and workers of different $B$. vosnesenskii colonies $\left(\sim-7{ }^{\circ} \mathrm{C}-\sim 5^{\circ} \mathrm{C}\right.$; Pimsler et al., 2020). These results, together with the $\mathrm{CT}_{\min }$-values obtained in our study, which are also measured as vial/cage temperature at chill coma point, are showing large species-specific magnitude of cold tolerances in bumble bees.

The difference in cold tolerance in workers of $B$. terrestris and B. impatiens might be due to more stable climatic conditions within the geographic range of $B$. impatiens, as several studies on terrestrial insects showed narrower thermal tolerance breadths in more stable climates (Hoffmann et al., 2013; Bozinovic et al., 2014; see also Sánchez-Echeverría et al., 2019). The difference could also be an unintended result of the intensive breeding practices with $B$. terrestris in Europe since the ' 80 s (Velthuis and Van Doorn, 2006). However, without determining the cold tolerance limits of wild-caught workers of each $B$. terrestris subspecies, this remains unclear. Future measurements of thermal tolerance breadths for wild $B$. terrestris workers need to reveal whether managed and wild $B$. terrestris have similar thermal tolerances and whether these results hold true for the other six, still untested, B. terrestris subspecies (Rasmont et al., 2008; Lecocq et al., 2016).

\subsection{Thermal tolerance in $B$. terrestris queens}

The $\mathrm{CT}_{\max }$ of queens was consistent within and among subspecies, at approximately $50{ }^{\circ} \mathrm{C}$. $\mathrm{CT}_{\max }$ was even strikingly constant in both workers and queens of all subspecies. A similar constant $\mathrm{CT}_{\max }$ between queen and workers has also been described for the little fire ant (Wasmannia auropunctata; Coulin et al., 2019). However, intraspecific differences were found in cold tolerance, with a significantly higher $\mathrm{CT}_{\min }$ in B. t. canariensis queens $\left(-6.4{ }^{\circ} \mathrm{C}\right)$ compared to the other two subspecies $\left(-7.8^{\circ} \mathrm{C}\right.$ and $-7.5^{\circ} \mathrm{C}$; B. t. audax and B. t. terrestris, respectively). As $B$. $t$. canariensis is endemic to the Canary Islands and found there solely (Rasmont et al., 2008; Lecocq et al., 2016), this warmer climate may explain the reduction in cold tolerance (e.g. via reduced plasticity or local adaptation; Gross, 2006; Diamond and Martin, 2016).

\subsection{Thermal tolerance breadth in B. terrestris}

Variable $\mathrm{CT}_{\min }$ and relatively constant $\mathrm{CT}_{\max }$ among B. terrestris subspecies confirmed the macro-physiological patterns of thermal tolerance in insect species along geographical gradients (Sunday et al., 2011; Hoffmann et al., 2013; Bozinovic et al., 2014; Lancaster 2016). Indeed, insects from lower altitudes and latitudes showed comparatively worse cold tolerance and no shifts in the ability to tolerate high temperatures, resulting in narrower thermal tolerance breaths (Angilletta, 2009; Oyen et al., 2016; Brans et al., 2017; Diamond et al., 2017).

Recent evidence on thermal tolerances in terrestrial ectotherms accumulates in favor of a variant of this climate variability hypothesis, the climate extremes hypothesis, which predicts that selection for thermal tolerances strongly depends on rare but extreme thermal events (see Sundays et al., 2019 and refs therein). Although the pattern of higher heat resistance in males of widespread bumble bee species compared to those of more restricted, declining, or alpine species (Martinet et al., 2015; Zambra et al., 2020) might fit to this rule, more research is necessary to confirm and reveal to which extent periods of such extreme weather conditions impacts thermal tolerance breadths of B. terrestris or bumble bees in general.

Furthermore, a higher heat tolerance has been described when comparing specimens over an urban-rural gradient (Brans et al., 2017; Diamond et al., 2017; Martin et al., 2019). Although Burdine and McCluney (2019) described variation in responses of bee species to urban climatic conditions, it is not known how bumble bees react under these changing conditions. Additional research assessing the impact of the heat island effect on wild B. terrestris -and bumble bees in general- is needed to better understand and assess the different ways that climate change can affect these important pollinators.

\subsection{Impact of body size and mass on thermal tolerance}

Although queens were bigger than workers, body size had no major impact on the critical thermal limits of queens and workers between subspecies. Indeed, the observed significant difference in $\mathrm{CT}_{\text {min }}$ between queens and workers remained, even after normalization by body size or body mass. Queens of $B$. t. terrestris were significantly heavier and bigger than those of B. t. audax and B. t. canariensis. This size difference might be due to multiple generations of intensive breeding towards bigger sized queens in bumble bee breeding facilities -as bigger bees have higher hibernation survival chances (Beekman et al., 1998). Although $B$. t. terrestris queens were bigger, critical thermal limits did not differ among the subspecies. No significant correlation with body size was also found in studying heat resistance in males of 10 bumble bee species (Zambra et al., 2020). Furthermore, other selective pressures influence body size in bumble bees, as has been discussed in Gérard et al. (2020), who found that queens of four bumble bee species became bigger over the last 100 year. This trend was not explained by global warming and the authors hypothesized that factors such as habitat fragmentation or agricultural intensification could better explain the observed pattern of bee body size shifts.

\subsection{Thermal tolerance differences between castes}

In our study, $\mathrm{CT}_{\min }$ was significantly lower in queens compared to workers both within and among subspecies. This difference between castes was not so unexpected. Workers can remain within the (warmer) nest during colder periods, forage during permissive ambient temperatures, and do not overwinter (Heinrich 1979; Goulson, 2010). Conversely, queens are exposed to low temperatures by default as they overwinter, and also forage under colder conditions to start-up their colony in the spring (Alford, 1975; Goulson, 2010). In other social insects, opposite results in thermal tolerances between castes were reported. Queens and workers of the acorn ant (Temnothorax curvispinosus) showed no difference in thermal tolerances (Diamond et al., 2017), while queens of $W$. auropunctata have a lower -but not significantly different- $\mathrm{CT}_{\min }$ than workers (Coulin et al., 2019). Furthermore, the different subcastes of the army ant (Eciton burchellii parvispinum) could tolerate other temperatures which were not explained by the obvious body sizes differences between the smaller (porters) and largest (soldiers) worker subcastes (Baudier and O'Donnell, 2018). As reviewed by Overgaard and MacMillan (2017), the $\mathrm{CT}_{\min }$ in insects is known to be dependent on the ability to maintain membrane polarity. Thus, although queens are much larger than workers (Alford, 1975; Goulson, 2010), the lower $\mathrm{CT}_{\min }$ in queens might be merely the effect of improved "defense" of their membrane polarities rather than due to differences in body size. 


\section{Conclusion}

In the present study, we determined the limits of thermal tolerance in workers and queens of three Bombus terrestris subspecies. Although queens of all subspecies tolerated cold better than workers (likely an adaptive response to selective pressures on queen cold hardiness which affects survival rate during overwintering), B. t. canariensis queens (originating from warmest environments) showed the lowest tolerance to cold. The remarkably high heat tolerance of both workers and queens suggests that $B$. terrestris populations may not be particularly vulnerable to global warming. However, more research on natural populations is needed to compare thermal limits within and among bumble bee species, and to which extent short and/or long periods of extreme weather conditions have an impact on the survival of $B$. terrestris populations. Hence, as intraspecific differences in thermal tolerance occur over bumble bee life stages and between subspecies, when assessing a given population's capacity to survive in changing climates, castes should be considered with regards to cold tolerance, while heat tolerance may be more consistent.

\section{Funding}

This work was supported by the Research Foundation Flanders (FWO) as part of the EOS project [CLiPS project, 30947854] and the FWO-research project [3G042618]. The funder had no role in study design, data collection and analysis, decision to publish, or preparation of the manuscript.

\section{Author contributions}

MK conceived and designed the experiments; ADB performed the experiment and collected the data; MK and ADB analyzed and interpreted the data; GS provided the resources; MK drafted the manuscript. All authors provided intellectual feedbacks on the manuscript and approved the final version of the manuscript.

\section{Declaration of competing interest}

The authors declare that they have no competing interests.

\section{Acknowledgements}

The authors would like to thank Alex Hart for English proofreading of the manuscript and XXX anonymous reviewers for their constructive comments which helped to improve our manuscript.

\section{Appendix A. Supplementary data}

Supplementary data to this article can be found online at https://doi. org/10.1016/j.jtherbio.2021.103002.

\section{References}

Abram, P.K., Boivin, G., Moiroux, J., Brodeur, J., 2017. Behavioural effects of temperature on ectothermic animals, Unifying thermal physiology and behavioural plasticity. Biol. Rev. 92, 1859-1876.

Abramoff, M.D., Magelhaes, P.J., Ram, S.J., 2004. Image processing with Image. J. Biophot. Int. 11, 36-42.

Alford, D.V., 1975. Bumblebees. Davies-Poynter, London, p. 352.

Angilletta, M.J., 2009. Thermal Adaptation, a Theoretical and Empirical Synthesis. Oxford University Press, New York, p. 289.

Bartomeus, I., Ascher, J.S., Wagner, D., Danforth, B.N., Colla, S., Kornbluth, S., Winfree, R., 2011. Climate-associated phonological advances in bee pollinators and bee-pollinated plants. Proc. Natl. Acad. Sci. U.S.A. 108, 20645-20649.

Baudier, K., O’Donnell, S., 2018. Complex body size differences in thermal tolerances among army ant workers (Eciton burchelii parvispinum). J. Therm. Biol. 78, 277-280.

Beekman, M., Van Stratum, P., Lingeman, R., 1998. Diapause survival and post-diapause performance in bumblebee queens (Bombus terrestris). Entomol. Exp. Appl. 89, 207-214.
Bishop, T.R., Robertson, M.P., Rensburg, B.J., Parr, C.L., 2017. Coping with the cold: minimum temperatures and thermal tolerances dominate the ecology of mountain ants. Ecol. Entomol. 42, 105-114.

Bozinovic, F., Orellana, M.J., Martel, S.I., Bogdanovich, J.M., 2014. Testing the heatinvariant and cold-variability tolerance hypotheses across geographic gradients. Comp. Biochem. Physiol. Mol. Integr. Physiol. 178, 46-50.

Brans, K.I., Jansen, M., Vanoverbeke, J., Tüzün, N., Stoks, R., De Meester, L., 2017. The heat is on, genetic adaptation to urbanization mediated by thermal tolerance and body size. Global Change Biol. 23 (12), 5218-5227.

Brett, J., 1956. Some principles in the thermal requirements of fishes. Q. Rev. Biol. 31, 75-87.

Bujan, J., Roeder, K.A., Yanoviak, S.P., Kaspari, M., 2020. Seasonal plasticity of thermal tolerance in ants. Ecology 101 (6), e03051. https://doi.org/10.1002/ecy.3051.

Burdine, J.D., McCluney, K.E., 2019. Differential sensitivity of bees to urbanizationdriven changes in body temperature and water content. Sci. Rep. 9, 1643. https:// doi.org/10.1038/s41598-018-38338-0.

Cameron, S.A., Sadd, B.M., 2020. Global trends in bumble bee health. Annu. Rev. Entomol. 65, 209-232.

Copernicus Climate Change Service (C3S), February 2020. ERA5: fifth generation of ECMWF atmospheric reanalyses of the global climate. vol. 2017. In: Copernicus Climate Change Service Climate Data Store (CDS), Accessed 13th. https,//cds. climate.copernicus.eu/cdsapp\#!/software/app-era5-explorer?tab=overview.

Coulin, C., de la Vega, G.J., Chifflet, L., Calcaterra, L.A., Schilman, P.E., 2019. Linking thermo-tolerances of the highly invasive ant, Wasmannia auropunctata, to its current and potential distribution. Biol. Invasions 21, 3491-3504.

Denlinger, D.L., 2002. Regulation of diapause. Annu. Rev. Entomol. 47, 93-122.

Deutsch, C.E., Tewksbury, J.J., Huet, R.B., Shedon, K.S., Ghalambor, C.K., Haak, D.C. Martin, P.R., 2008. Impacts of climate warming on terrestrial ectotherms across latitude. Proc. Natl. Acad. Sci. U.S.A. 105 (15), 6668-6672.

Diamond, S.E., Chick, L., Perez, A., Strickler, S.A., Martin, R.A., 2017. Rapid evolution of ant thermal tolerance across an urban-rural temperature cline. Biol. J. Linn. Soc. 121, 248-257.

Diamond, S.E., Martin, R.A., 2016. The interplay between plasticity and evolution in response to human-induced environmental change. F1000 Research 5, 2835. https://doi.org/10.12688/f1000research.9763.1.

Dotson, A., 2017. Seasonal Variation in Abundance and Thermal Tolerance of Bumble Bees (Bombus) in Grand Teton National Park. University of Wyoming. https ://mountainscholar.org/bitstream/handle/20.500.11919/1438/STUW_HT_2 017_Dotson_Annika.pdf? sequence=1.

Gérard, M., Martinet, B., Maebe, K., Marshall, L., Smagghe, G., Vereecken, N.J., Vray, S., Rasmont, P., Michez, D., 2020. Shift in size of bumblebee queens over the last century. Global Change Biol. https://doi.org/10.1111/gvb.14890.

Goulson, D., 2010. Bumblebees, Behaviour, Ecology and Conservation. Oxford University Press, Oxford, p. 336.

Gross, L., 2006. Islands spark accelerated evolution. PLoS Biol. 4 (10), e334. https://doi. org/10.1371/journal.pbio.0040334.

Hahn, D.A., Denlinger, D.L., 2007. Meeting the energetic demands of insect diapause: nutrient storage and utilization. J. Insect Physiol. 53 (8), 760-773.

Hahn, D.A., Denlinger, D.L., 2011. Energetics of insect diapause. Annu. Rev. Entomol. 56, 103-121.

Hamblin, A.L., Youngsteadt, E., López-Uribe, M.M., Frank, S.D., 2017. Physiological thermal limits predict differential responses of bees to urban heat island effects. Biol. Lett. 13 (6), 20170125. https://doi.org/10.1098/rsbl.2017.0125.

Heinrich, B., 1979. Bumblebee Economics. Havard University Press, Cambridge, Massachusetts and London, p. 159.

Heinrich, B., 1993. Hot-blooded Insects, Strategies and Mechanisms of Thermoregulation. Harvard University Press, Cambridge, p. 523.

Hoffmann, A.A., Chown, S.L., Clusella-Trullas, S., 2013. Upper thermal limits in terrestrial ectotherms, how constrained are they? Funct. Ecol. 27, 934-949.

IBM Corp, 2017. IBM SPSS Statistics for Windows. IBM Corp. Armonk, NY, Version 25.0.

Janzen, D.H., 1967. Why mountain passes are higher in the tropics. Am. Nat. 101, 233-249.

Kellermann, V., Overgaard, J., Hoffmann, A.A., Fløjgaard, C., Svenning, J.-C., Loeschcke, V., 2012. Upper thermal limits of Drosophila are linked to species distributions and strongly constrained phylogenetically. Proc. Natl. Acad. Sci. U.S.A. 109 (40), 16228-16233.

Kerr, J.T., Pindar, A., Galpern, P., Packer, L., Potts, S.G., Roberts, S.M., Rasmont, P., Schweiger, O., Colla, S.R., Richardson, L.L., Wagner, D.L., Gall, L.F., Sikes, D.S., Pantoja, A., 2015. Climate change impacts on bumble bees converge across continents. Science 349, 177-180.

Kovac, H., Käfer, H., Stabentheiner, A., Costa, C., 2014. Metabolism and upper thermal limits of Apis mellifera carnica and A. m. ligustica. Apidologie 45, 664-677.

Lancaster, L.T., 2016. Widespread range expansions shape latitudinal variation in insect thermal limits. Nature Clim. Change 6, 618-621.

Lecocq, T., Coppée, A., Michez, D., Brasero, N., Rasplus, J.-Y., Valterová, I., Rasmont, P., 2016. The alien's identity, Consequences of taxonomic status for the international bumblebee trade regulations. Biol. Conserv. 195, 169-176.

Marshall, L., Biesmeijer, J.C., Rasmont, P., Vereecken, N.J., Dvorak, L., Fitzpatrick, U., Francis, F., Neumayer, J., Ødegaard, F., Paukkunen, J.P.T., Pawlikowski, T., Reemer, M., Roberts, S.P.M., Straka, J., Vray, S., Dendoncker, N., 2018. The interplay of climate and land use change affects the distribution of EU bumblebees. Global Change Biol. 24, 101-116.

Martin, R.A., Chick, L.D., Yilmaz, A.R., Diamond, S.E., 2019. Evolution, not transgenerational plasticity, explains the adaptive divergence of acorn ant thermal tolerance across an urban-rural temperature cline. Evol. Appl. 12, 1678-1687. 
Martinet, B., Lecocq, T., Smet, J., Rasmont, P., 2015. A protocol to assess insect resistance to heat waves, applied to bumblebees (Bombus Latreille, 1802). PLoS One 10, e0118591. https://doi.org/10.1371/journal.pone.0118591.

Overgaard, J., MacMillan, H.A., 2017. The integrative physiology of insect shill tolerance. Annu. Rev. Physiol. 79, 187-208.

Owen, E.L., Bale, J.S., Hayward, S.A.L., 2013. Can winter-active bumble bees survive the cold? Assessing the cold tolerance of Bombus terrestris audax and the effects of pollen feeding. PloS One 8, e80061. https://doi.org/10.1371/journal.pone.0080061.

Oyen, K.J., Giri, S., Dillon, M.E., 2016. Altitudinal variation in bumble bee (Bombus) critical thermal limits. J. Therm. Biol. 59, 52-57.

Oyen, K.J., Dillon, M.E., 2018. Critical thermal limits of bumble bees (Bombus impatiens) are marked by stereotypical behaviors and are unchanged by acclimation, age, or feeding status. J. Exp. Biol. 1, jeb165589. https://doi.org/10.1242/jeb.165589.

Pimsler, M.L., Oyen, K.J., Herndon, J.D., Jackson, J.M., Strange, J.P., Dillon, M.E., Lozier, J.D., 2020. Biogeographic parallels in thermal tolerance and gene expression variation under temperature stress in a widespread bumble bee. Sci. Rep. 10 (1), 17063.

Potts, S.G., Biesmeijer, J.C., Kremen, C., Neumann, P., Schweiger, O., Kunin, W.E., 2010 Global pollinator declines, trends, impacts and drivers. Trends Ecol. Evol. 25, 345-353.

Pyke, G.H., Thomson, J.D., Inouye, D.W., Miller, T.J., 2016. Effects of climate change on phenologies and distributions of bumble bees and the plants they visit. Ecosphere 7, $1-19$.

Rasmont, P., Coppée, A., Michez, D., De Meulemeester, T., 2008. An overview of the Bombus terrestris (L.1758) subspecies (Hymenoptera, Apidae). Ann. Soc. Entomol. Fr 44, 243-250.
Rasmont, P., Franzen, M., Lecocq, T., Harpke, A., Castro, L., Cederberg, B., Dvorak, L., Fitzpatrick, U., Gonseth, Y., Haubruge, E., et al., 2015. Climatic Risk and Distribution Atlas of European Bumblebees. Pensoft, Sofia, p. 236.

Robertson, R.M., Spong, K.E., Srithiphaphirom, P., 2017. Chill coma in the locust, Locusta migratoria, is initiated by spreading depolarization in the central nervous system. Sci. Rep. 7, 10297. https://doi.org/10.1038/s41598-017-10586-6.

Sánchez-Echeverría, K., Castellanos, I., Mendoza-Cuenca, L., Zuria, I., Sánchez-Rojas, G., 2019. Reduced thermal variability in cities and its impact on honey bee thermal tolerance. Peer J 7, e7060. https://doi.org/10.7717/peerj.7060.

Sunday, J.M., Bates, A.E., Dulvy, N.K., 2011. Global analysis of thermal tolerance and latitude in ectotherms. Proc. R. Soc. B 278, 1823-1830.

Sunday, J.M., Bennett, J.M., Calosi, P., Clusella-Trullas, S., Gravel, S., Hargreaves, A.L., Leiva, F.P., Verberk, W.C.E.P., Olalla-Tárraga, M.Á., Morales-Castilla, I., 2019. Thermal tolerance patterns across latitude and elevation. Phil. Trans. R. Soc. B 374, 20190036.

Sunday, J.M., Bates, A.E., Kearney, M.R., Colwell, N.L., Dulvy, N.K., Longino, J.T., Huey, R.B., 2014. Thermal-safety margins and the necessity of thermoregulatory behavior across latitude and elevation. Proc. Natl. Acad. Sci. U.S.A. 111 (15), $5610-5615$.

Vanbergen, A.J., the Insect Pollinators Initiative, 2013. Threats to an ecosystem service, pressures on pollinators. Front. Ecol. Environ. 11 (5), 251-259.

Velthuis, H.H.W., van Doorn, A., 2006. A century of advances in bumblebee domestication and the economic and environmental aspects of its commercialization for pollination. Apidologie 37, 421-451.

Zambra, E., Martinet, B., Brasero, N., Michez, D., Rasmont, P., 2020. Hyperthermic stress resistance of bumblebee males, test case of Belgian species. Apidologie. https://doi. org/10.1007/s13592-020-00771-4. 